\title{
Antenna Systems for Base Station Applications
}

\author{
Chetanjot Kaur, Narwant Singh Grewal
}

\begin{abstract}
Base Station is the primary unit of any mobile communication system. An antenna is the most important part of the Base Station as it is responsible for exchange of all the electrical signals and electromagnetic waves radiations. From the last two decades there is huge advancement in the mobile communications and so as in the antennas for the base stations. This advancement gives rise to new designs of antennas with different specifications for different applications. In this paper, we discussed different geometries, designed earlier for the base station applications. The structures and respective results of antennas are discussed in the paper.
\end{abstract}

Index Terms: Base Station, Dipole Antenna, Dual Polarization, Patch antennas, Slot antennas.

\section{INTRODUCTION}

Base Station is the basic unit between the mobile switching center and the users. In the last two decades there is an immense growth in the world of mobile communications. The technology has been upgraded from the GSM to the 2G।3G 44 G and LTE (Long Term Evolution).

With this, the antennas for the base stations are also getting advanced day by day. Various types of geometries have been designed for the base station applications like Microstrip Patch antennas [1], slot antenna[2], dipole antenna [3], stacked patch antennas[4] etc. Antenna arrays have also been designed for the better results and performance of the antenna. The various types of antenna and their results are compared here. The most used antenna for the Base stations are dipole antennas.

\section{REQUIREMENTS FOR BASE STATION ANTENNAS}

The basic requirements of base station antennas are the gain, beam tilt, beamwidth, polarization, bandwidth, antenna isolation etc. The antennas are more likely to be vertical arrays as vertical arrays create gain in the vertical plane or in the plane where energy is needed. The combination of vertical array and reflector is used for the directional antenna. The coverage of service area of antenna can be determined by vertical and horizontal beamwidth. When the gain is higher the beamwidth is narrower as the gain and beamwidth are strongly related to each other.

The beam tilts are of two types: Electrical and Mechanical tilt. Co-channel Interference in a service area can be reduced by combining electrical and mechanical tilts. That means beam tilt provides good coverage in the service area. The bandwidth

Revised Manuscript Received on June 15, 2019.

Chetanjot Kaur, Department of Electronics and Communication Engineering, Guru Nanak Dev Engineering College, Ludhiana, India. Narwant Singh Grewal, Department of Electronics and Communication Engineering, Guru Nanak Dev Engineering College, Ludhiana, India. Third of antenna is defined by maximum of VSWR (Voltage Standing Wave Ratio) that is often 1.5.

The bandwidth is affected by the type of array feed used. Polarization is also an important requirement of Base Station antenna. Mostly the 45-degree slant polarization was used. Dual Polarization is being used widely as it helps in reducing the installation area and also reduces the signal fading. For the better performance of the antenna it should be coupled tightly that is it should be highly isolated. By reducing the physical separation between the antennas the isolation can be increased.

\section{TYPES OF ANTENNAS DESIGNED FOR BASE STATIONS}

There are different types of geometries being designed for base station applications. With the increase in the use of mobile communication, there has been continuing development in the base stations. This development raises the demand of the new antenna designs for the better performance of the base stations. The different types of antennas designed are discussed here.

\section{A. Microstrip Patch Antenna}

The simplest designed antennas for base stations are microstrip patch antennas. It has simple geometry and planar structure. The microstrip patch antennas consist of a ground plane and a patch (Fig.1). The microstrip antennas with slots are generally compact in size. Thus they can be used for various applications including base station applications.

A dual polarization based single patch microstrip antenna is designed as in reference number [1] to work in broadband. The antenna designed is highly isolated and fed by two hybrid input ports: one is in- phase coupled feed, second is out-phase coupled feed with $\mathrm{H}$-slot and rectangular slot respectively. The center frequency of the designed antenna was $1800 \mathrm{MHz}$ with impedance bandwidths $261 \mathrm{MHz}$ and $359 \mathrm{MHz}$.

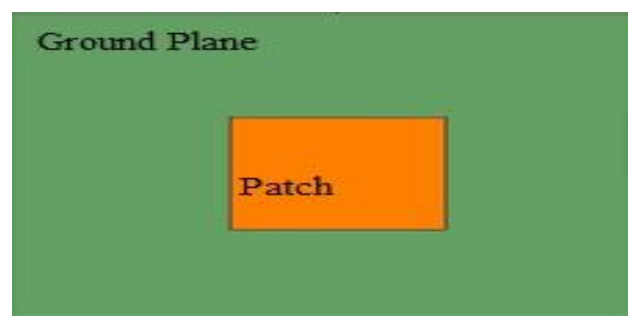

Figure 1 Simple Microstrip Patch Antenna

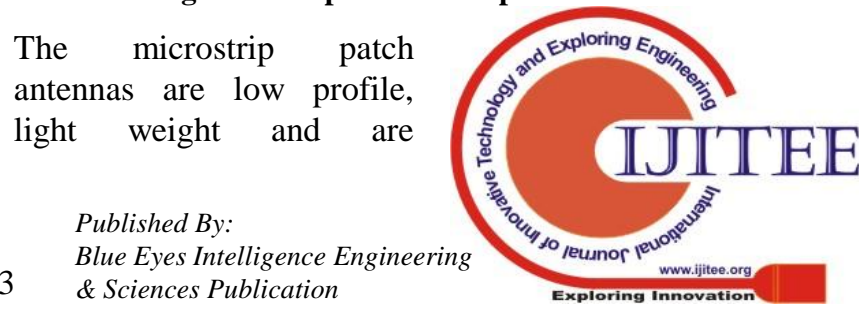


compatible with integrated circuits because of their compact size. Thus, they are used for various applications. The microstrip patch antenna array is also designed for base station applications as in reference number [5]. The antenna array is designed to work in dual frequency band.

\section{B. Microstrip Stack Patch Antenna}

Microstrip stack patch antenna consists of two or more than two layers of patches stacked one on another. These antennas have a slightly better bandwidth than the simple microstrip antenna. Microstrip stack patch antennas are also designed with dual polarization to achieve the desired results for the base station applications.

In reference [4] microstrip stack patch antenna with dual polarization for micro base stations is designed. The antenna consists of three elements rectangular patches, substrate and reflector. The stacked patches are shown in figure 2 . The impedance bandwidth of the designed antenna is $14.6 \%$ from 1710 to $1980 \mathrm{MHz}$ frequency range. Its gain is $12 \mathrm{dBi}$. The dual feed technique is used for the dual polarization. The antenna designed was a low profile, highly reliable, dual polarized and can be fabricated very easily thus very suitable for micro base stations.

Many microstrip stack patch antennas are designed [4], [6]-[7] for the base station applications. In reference [7], antenna is designed to work in UMTS (Universal Mobile Telecommunication System) and WLAN (Wireless Local Area Network). Dual polarization is used to achieve the desired results in the required frequency bands.

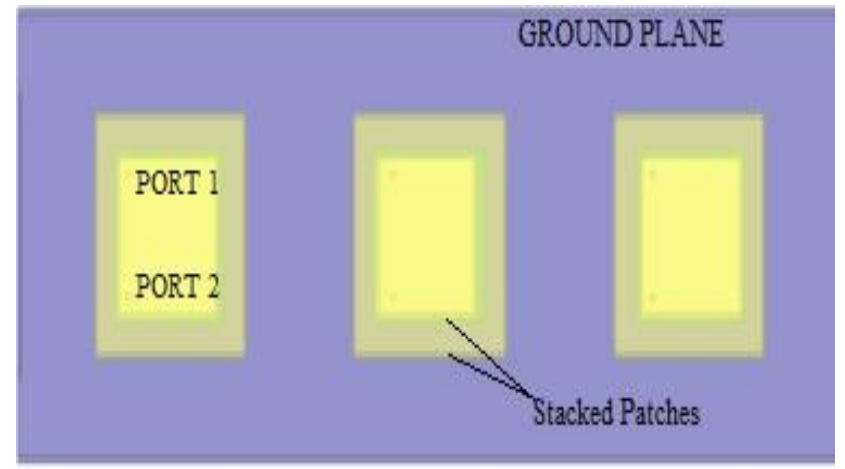

Figure 2 Microstrip Stacked Patch Antenna [4]

\section{Slot Antenna}

The slot antennas are also a good choice for the base station applications. [2], [8]-[12] Due to slots the size of the antennas can be minimized. The slots radiate electromagnetic waves similar to the dipole antennas. The shape, size and driving frequency determine the radiation pattern of the antenna. Figure 3 shows the stepped slots which are cut diagonally. This is an example of the geometry being designed for the base station antenna.

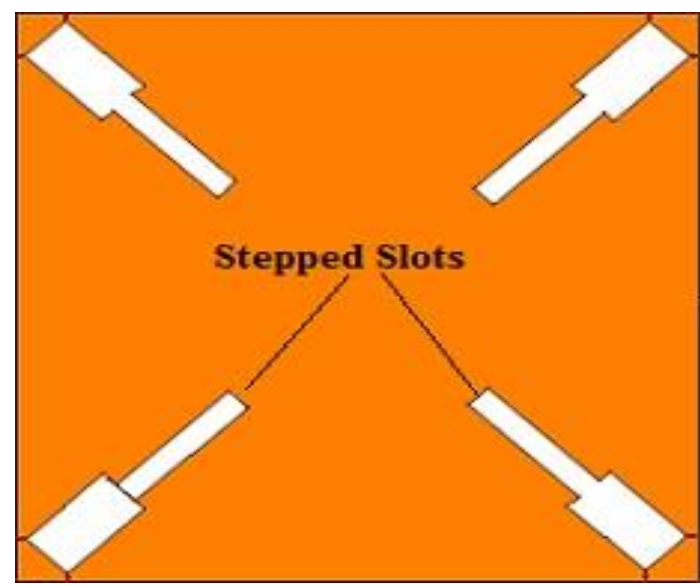

Figure 3 Slot Antenna

In reference [2], the slot antenna designed is the stepped slot antenna array with dual polarization. The antenna is composed of two pairs of SI slots excited by two orthogonal stepped microstrip feedlines. The four element antenna array was further designed. The antenna achieved an overlapped band of $620 \mathrm{MHz}$ for both polarizations. The array prototype achieved a wide band in the range of 1.69-2.5 GHz, which covers GSM, PCS, UMTS and WLAN applications. The antenna achieved a good unidirectional radiation because of the presence of the reflector with a specific height and had cross polarization less then $-27 \mathrm{~dB}$. Thus the slot antennas are widely used for the various applications.

In reference [11], an H-shaped slot antenna with Co-planar feedline is designed to work at $2.4 \mathrm{GHz}$ frequency. The antenna achieved bandwidth of $17 \%$ approximately and the isolation up to $-32 \mathrm{~dB}$. The designed antenna can be used for the Base Station as well as for the WLAN applications. Figure 4 shows the antenna geometry for reference [11].

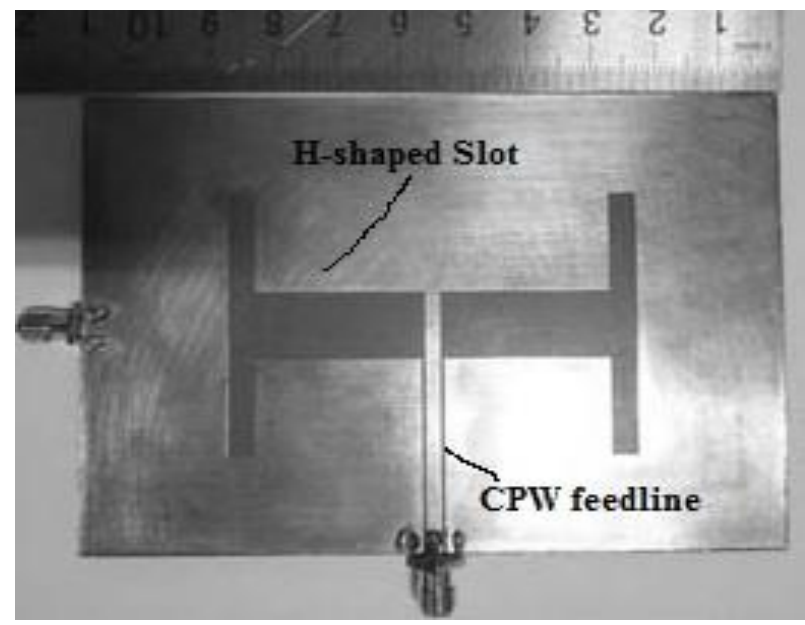

Figure 4 H-shaped Slot Antenna [11]

\section{Dipole Antenna}

Dipole antennas are designed mostly for the base station applications but they have complex geometries as compared to other antennas. But the results achieved in the dipole antennas are much better than other designed geometries. [13] - [17]. The dipole antenna designed [3]contains four parts: a lower-band element, an 
upper-band element, arc-shaped baffle plates, and a box-shaped reflector (fig.5).

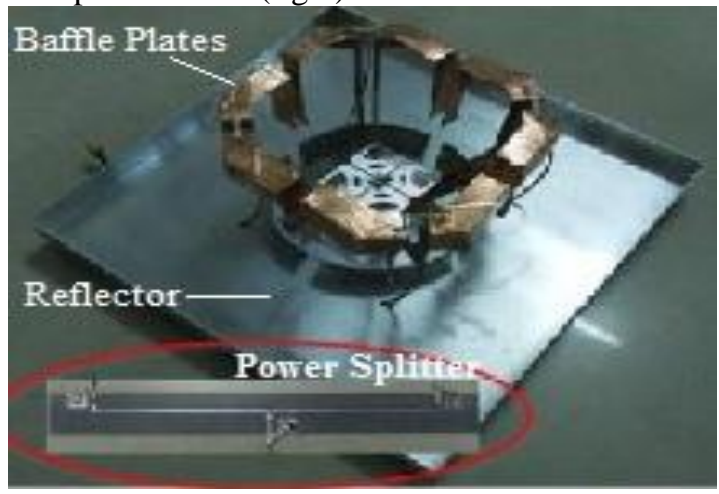

Figure 5 Dipole Antenna [3]

The lower-band element consists of two pairs of dipoles with additional branches for bandwidth enhancement. The designed antenna covered dual broadband from $700 \mathrm{MHz}-1200 \mathrm{MHz}$ and $1700-2710 \mathrm{MHz}$ thus antenna is suitable to be used for all $2 \mathrm{G}, 3 \mathrm{G}$ and $4 \mathrm{G}$ applications. The antenna achieved high isolation and good radiation performance.

In reference [13], the magneto-electric dipole antenna with T-shaped strips are designed. The antenna bandwidth achieved is $65.9 \%$ and the isolation of $36 \mathrm{~dB}$. The gain achieved by the dipole antenna is $9.5 \mathrm{dBi}$. The antenna design consists of two simple feed lines. The highly isolated antenna gives very stable results for operating frequency and radiation pattern.

There are many dipole antennas with different geometries designed for the Base Station applications [13]-[20].The results of different antennas are shown in the Table 1.

Table 1 Characteristics of various Dipole Antennas designed for Base Station Applications

\begin{tabular}{|c|c|c|c|c|}
\hline Ref. & $\begin{array}{c}\text { Operating } \\
\text { Frequency } \\
(\mathrm{GHz})\end{array}$ & $\begin{array}{c}\text { Gain (in } \\
\mathrm{dBi})\end{array}$ & Polarization & $\begin{array}{c}\text { Isolation } \\
(\mathrm{dB})\end{array}$ \\
\hline$[13]$ & $\begin{array}{c}2.109,2.707, \\
3.306\end{array}$ & 9.5 & Dual & 36 \\
\hline$[14]$ & $1.71,2.2,2.69$ & 9 & Dual & 40 \\
\hline$[15]$ & $1.71-2.69$ & 9 & Dual & 43 \\
\hline$[16]$ & $1.7-2.5$ & 6.5 & Single & - \\
\hline$[17]$ & $1.68-2.68$ & -2.47 & Dual & 25.4 \\
\hline$[18]$ & $1.7-2.7$ & $13.1-15.4$ & Dual & $<22$ \\
\hline$[19]$ & $2.32-4.03$ & 7.5 & Dual & 33 \\
\hline$[20]$ & $275-465 \mathrm{MHz}$ & $12-14$ & Dual & $<30$ \\
\hline
\end{tabular}

The different dipole antenna arrays are also designed for the base station applications with slot antennas [14], bowtie dipole antenna [21], and MIMO antenna arrays using dipole [22]-[24]. The resonator loaded dipole antenna and many dipole antennas with anti- interference are also designed for the base station and different applications like WLAN [25]-[27].

The dipole antennas are used mostly because they give high bandwidth than microstrip or slot antennas. Other antennas give $20 \%$ of bandwidth approximately but when they are used with the dipole antenna, its bandwidth as well as performance increases.

There are many other antenna design and geometries used for base station applications like novel dual polarized antennas [28]-[29]. The orthogonal coupled loop antennas are also designed for better bandwidth of the base station antenna. The various antennas are designed with dual polarization as the dual polarization helps in decreasing the installation area of the antenna arrays. Some dual dipole with dual polarization is also designed [31].

The antenna results also depend on the feeds that are being applied. The different feeds that are applied to antennas are Microstrip feed, Probe feed to patch, Dual feeds etc. The microstrip feedlines are applied orthogonally for the dual polarization in the base station antennas as in reference [2].

The only disadvantage of the dipole antenna is that the geometry becomes complex and the height of the antenna increases.

The reflectors are used mostly in the case of the slot antennas for getting the unidirectional radiation pattern. Mostly antennas being designed for base station are having reflectors with some height as it improves the directivity of the antenna. Dipole antennas are also having reflectors [3] but the height of reflector is less than that of the height of the reflectors being used in the slot antennas.

The optimal results for any antenna geometry can be obtained by applying optimization techniques. Genetic Algorithm is used for the optimal results for the $3 \mathrm{G}$ base station [32]. Optimization techniques are approached in antenna designing for improving output parameters of antenna.

\section{IV.CONCLUSION}

There are number of antennas being designed for the Base Station applications with different geometries and specifications. We can see that most commonly used antennas are dipole antennas and slot antennas. Slot antennas are preferred because of its compact size and easy geometry as it can be used for many wireless devices.

Due to its compact size it can be used for the IoT (Internet of Things) projects. On the other hand dipole antennas are preferred because of its better performance as we can see that the dipole antennas have high isolation and better operating frequency to that of the slot antennas. However dipole antennas with slots are also used for the different applications. Many of the antennas designed for the Base Station applications can also be used for other applications like WLAN, WiMAX etc.

\section{REFERENCES}

1. T.W. Chiou and K.L. Wong, "Broad-Band Dual-Polarized Single 
Microstrip Patch Antenna with High Isolation and Low Cross Polarization," IEEE Transactions on Antennas and Propagation, vol.50, no. 3, 2002, pp. 399-401.

2. R. Lian, Z. Wang, Y. Yin, et al., "Design of a Low-Profile Dual-Polarized Stepped Slot Antenna Array for Base Station," DOI 10.1109/LAWP.2015.2446193, IEEE Antennas and Wireless Propagation Letters, 2015.

3. H. Huang, Y. Liu and S. Gong, "A Dual-Broadband, Dual-Polarized Base Station Antenna for 2G/3G/4G Applications," IEEE Antennas and Wireless Propagation Letters, vol.16, 2017, pp. 1111-1114.

4. Y. He, C. Li and J. Yang, "A Low-Profile Dual-Polarized Stacked Patch Antenna for Micro-Base-Station Applications," IEEE MTT-S International Wireless Symposium (IWS), 2018

5. K. Moradil and S. Nikmehr, "A Dual Band Dual Polarized Microstrip Array Antenna for Base Stations,"Progress In Electromagnetics Research, , 2012Vol. 123, 527\{541.

6. Y.Gao, R. Ma and Y. Wang et.al, "Stacked Patch Antenna with Dual-Polarization and Low Mutual Coupling for Massive MIMO," IEEE Transactions on Antennas and Propagation, vol.64, no 10, , 2016. pp. 4544-4549

7. A. A. Serra, P. Nepa, G. Manara, G. Tribellini, and S. Cioci, "A Wide-Band Dual-Polarized Stacked Patch Antenna,'IEEE Antennas and Wireless Propagation Letters VOL. 6, 2007

8. X. L. Jiang, Z. J. Zhang, Y. Li, and Z. H. Feng, "A wideband dual-polarized slot antenna," IEEE Antennas Wireless Propagation Letters, vol. 12, Jul. 2013, pp. 1010-1013.

9. R.V.S. Krishna and R. Kumar, "A Dual-Polarized Square Ring Slot Antenna for UWB, Imaging and Radar Applications," IEEE Antennas Wireless Propagation Letters, vol.15, 2016, pp. 195-198.

10. R.Kumar, R. K. Khokle, and R. V. S. R. Krishna, "A Horizontally Polarized Rectangular Stepped Slot Antenna for Ultra- Wide Bandwidth with Boresight Radiation Patterns,"'IEEE Transactions on Antennas and Propagation, vol. 62, NO. 7, JULY 2014.

11. W. Li, Z. Xia, B. You, Y. Liu and Q. Liu, "Dual-Polarized H-Shaped Printed Slot Antenna,"DOI 10.1109/LAWP.2016.2646805, IEEE Antennas and Wireless Propagation Letters, 2016.

12. Y. Liu and Z. Tu, "Compact Differential Band-Notched Stepped-Slot UWB-MIMO Antenna with Common-Mode Suppression," IEEE Antennas Wireless Propagation Letters, DOI 10.1109/LAWP.2016.2592179.

13. Polarized Magneto-Electric Dipole Antenna with Simple Feeds," IEEE Antennas and Wireless Propagation Letters, vol.8, pp. 60-63, 2009.

14. X.Gao, H. W. Lai, K. Kan So, et al., "Dual-Polarized Antenna Element for LTE Applications", IEEE International Workshop on Electromagnetics, Applications and Student Innovation Competition, DOI 10.1109/iWEM.2013.6888800, August 2013.

15. Y. Liu, H. Yi, F. W. Wang, and S. X. Gong, "A novel miniaturized broadband dual-polarized dipole antennas for base station," IEEE Antennas Wireless Propagation Letters, vol. 12, Oct. 2013. pp. 1335-1338.

16. W. Di, Y. Yingzeng, G.Minjun and S. Renqiang, "Wideband Dipole Antenna for 3G Base Stations," IEEE International Symposium on Microwave, Antenna, Propagation and EMC Technologies for Wireless Communications Proceedings, 2005.

17. H.Huang, Y. Liu and S. Gong, "A Broadband Dual-Polarized Base Station Antenna with Anti-Interference Capability,"IEEE Antennas and Wireless Propagation Letters, vol.16, 2017.

18. H. Huang, Y. Liu and S. Gong, "A Broadband Dual-Polarized Base Station Antenna with Sturdy Construction," IEEE Antennas and Wireless Propagation Letters, 2017,vol. 16, pp. 665-668.

19. G. Zhang, L. Sun and B. Sun, "A Wideband Dual-Polarized Antenna Using Planar Quasi-Open-Sleeve Dipoles for Base Station Applications," DOI 10.1155/2015/164392, International Journal of Antennas and Propagation, 2015.

20. X. L. Jiang, Z. J. Zhang and Y. Li et.al, "A low-cost dual-polarized array antenna etched on a single substrate," IEEE Antennas Wireless Propagation Letters, vol.12, Mar. 2013,pp.265-268.

21. Y.Cui, R.Li, and H. Fu, "A Broadband Dual-Polarized Planar Antenna for $2 \mathrm{G} / 3 \mathrm{G} / \mathrm{LTE}$ Base Stations,"IEEE Transactions on Antennas and Propagation, vol.62.no.9, September 2014.

22. Y. Cui , L. Wu and R. Li, "Bandwidth Enhancement of a Broadband Dual-Polarized Antenna for 2G/3G/4G and IMT Base Stations,"IEEE Transactions on Antennas and Propagation,vol,66.no.12, December,2018

23. Q. Zhang and Y.Gao, "A Compact Broadband Dual-Polarized Antenna Array for Base Stations," IEEE Antennas and Wireless Propagation Letters, vol.17, no. 6, June 2018.
24. H. Zhai, Lei Xi, Y. Zang, and Long Li, "A Low Profile Dual-polarized High Isolation MIMO Antenna Arrays for Wideband Base Station Applications,"'IEEE Transactions on Antennas and Propagation, DOI 10.1109/TAP.2017.2776346.

25. H. Zhai, J. Zhang, Y. Zang, Q. Gao and C. Liang, "An LTE Base-Station Magneto-electric DipoleAntenna with Anti-Interference Characteristics and Its MIMO System Application,"IEEE Antennas and Wireless Propagation Letters, vol.14, 2015

26. J.N. Lee, K.C. Lee and P.J. Song, "The Design of a Dual-Polarized Small Base Station Antenna with High Isolation Having a Metallic Cube,",'IEEE Transactions on Antennas and Propagation, vol.63, no.2, February 2015

27. R. Wu and Q. Chu, "Resonator-Loaded Broadband Antennafor LTE700/GSM850/GSM900 Base Stations,","IEEE Antennas and Wireless Propagation Letters, vol.16, 2017.

28. Y. He, W. Tian and L. Zhang, "A Novel Dual-Broadband Dual-Polarized Electrical Down-tilt Base Station Antenna for 2G/3G Applications," IEEE Access, vol.5, June 2017.

29. M. M. Fadoul, T. A. Rahman, and A. Moradikordalivand, "Novel Planar Antenna for Long Term Evolution (LTE)," International Journal of Information and Electronics Engineering, Vol. 4, No. 1, January 2014.

30. A. Elsherbini, J. Wu and K. Sarabandi, "Dual Polarized Wideband Directional Coupled Sectorial Loop Antennas for Radar and Mobile Base Stations Applications,"IEEE Transactions on Antennas and Propagation,DOI 10.1109/TAP.2015.2392773.

31. Y. Cui, X. Gao, H. Z. Fu, Q. Xin Chu, and R. Li, "Broadband Dual-Polarized Dual-Dipole Planar Antennas, ” IEEE Antennas and Propagation Magazine, pp. 77-87, December 2017.

32. . SEbadi, N.Amiri and L. Forooraghi, " A Low Side lobe level Non-equispaced Microstrip Array Antenna Design for BTS Application Using Genetic Algorithm,'IEEE International Symposium on Microwave, Antenna, Propagation and EMC Technologies for Wireless Communications Proceedings ,2005.

\section{AUTHORS PROFILE}

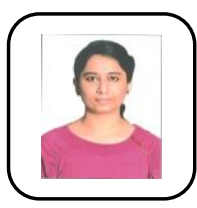

Chetanjot Kaur is currently pursuing M.Tech from Department of Electronics and Communication of Guru Nanak Dev Engineering College, Ludhiana. She received her B. Tech degree in Electronics and Communication Engineering from Gulzar Group of Institutes, Ludhiana in 2016. Her research area is Antenna Designing.

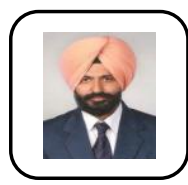

Narwant Singh Grewal received the B.E., M.Tech and $\mathrm{Ph}$. D degrees in Electronics and Communication Engineering. He is currently working as an Assistant Professor inGuru Nanak Dev Engineering College, Ludhiana. He has 22 conferences, 4 National Journal and 7 International Journal Publications. His research interests are Antenna array failure system, Optimization techniques and Digital system Design. He is member of I.S.T.E, IEEE, I.E. and I.E.T.E. 